\title{
The Importance of Communication and Interpersonal Relations in Agribusiness Enterprises
}

\author{
Dionise Magna Juchem \\ University of León, León, Spain \\ The Federal Institute Farroupilha, Júlio de Castilhos, Brazil \\ Edgardo Alfredo Herrera Céspedes \\ Catholic University, Porto Alegre, Brasil \\ The Federal Institute of Mato Grosso do Sul, Campo Grande, Brazil
}

\begin{abstract}
This study aims to investigate the importance of communication and interpersonal relationship in the development of activities in the agribusiness ventures. The study methodology includes theoretical search and field research with descriptive exploratory method. The results indicate that there is need to be investing in people management, demonstrating that there is still much to be improved, particularly as regards the development of workers. In this sense, it is recommended that invested more in continuing education and refresher courses for staff development, entrepreneurship training to show concern in giving them the opportunity to grow personally and professionally and still have other competitive advantages such as increased productivity, reduced costs, improved quality, and reduction in turnover of staff.
\end{abstract}

Keywords: entrepreneurship, communication, interpersonal, agribusiness

\section{Introduction}

Communication is one of the elements that distinguish organizations from other, and it is by means of business communications that strategic decisions can be reached at all company levels.

It is through communication that people interact and develop their activities in organizations. Interpersonal relationships are of fundamental importance, because people need to feel welcomed and heard. The relationship between people is important for motivation and development of productive activities on a daily basis.

When there is no adequate interpersonal relationship, people feel discouraged, fail to adequately perform their activities and many even develop emotional disorders.

Dionise Magna Juchem, Ph.D. in Business Administration and Business Management, University of León, with Diploma recognized by the USP, Professor of the Federal Institute Farroupilha.

Edgardo Alfredo Herrera Céspedes, MBA in Materials and Technology, Catholic University, Professor of the Federal Institute of Mato Grosso do Sul.

Correspondence concerning this article should be addressed to Dionise Magna Juchem or Edgardo Alfredo Herrera Céspedes, Rua Cisalpina Costa Monteiro, 11 jardim Panamá, Campo Grande, MS Brasil, CEP $79113030 . \quad$ E-mail: dionisejuchem@gmail.com; edgardoahc@hotmail.com. 
Therefore, this study aims to investigate the importance of communication and interpersonal relationships in the development of activities in the agribusiness ventures in the state of Mato Grosso do Sul, Brazil. Being research problem: how the integration of the subsystems of work occurs, the ability to work in teams, interpersonal skills of communication, and how are conflicts handled internally, performance and job satisfaction?

\section{Organizational Behavior}

Such conduct is defined as all expressions that showcase the personality, experience, culture, and expectations of the individual. The formation of the behavior of every human being is related to the environment to which it is exposed. In this sense, Chanlat (1999) said it was from the perception of the social environment that a person organized information received and those related to positive or negative affection, thus forming interpersonal relationships. The author explains that it is from the approval of others or their own social group that attitudes develop and the individual will incorporate them into their behavior.

In this sense, it is clear that how the individual demonstrates his/her vision of the world and its people depends on aggregate values, these values being the mental components of every human being. So the individual, who has good quality mental models, will have a better representation of their reality (Chanlat, 1999).

Personal values are formed through relationships with people and organizations and also built based on values such as discipline, loyalty, honesty, perseverance, and respect, which are incorporated into the organizational mission. The values obtained must be explicitly stated in all actions, forming a pillar to support the organizational business definition.

Therefore, management must be concerned with the formation of a team that acts in a harmonic way, where the working groups have a common vision applied to the development of their tasks, performing functions with regard to hierarchy, diversity, and individuality of each other, and therefore the company will be forming a stellar team.

Pires (2003) explained that each person was unique in their way of thinking and acting, so interpersonal relationships promote empathy, where everyone respects and accepts each other's differences, thus forming a harmonious coexistence.

In the business environment, Caparoz (2005) explained that the interpersonal relationship foster the motivation of the work team, promoting the development of services and quality products. Accordingly, it can be said that one factor that contributes the most to the quality of interpersonal relationship is the motivation with which people develop their activities, considering the importance of motivational factors forming what is called the behavior of people in organizations.

\section{Communication and Organizational Environment}

Organizational environment is the context in which the company develops, having as the main elements-employees, customers, suppliers, and competitors. The organizational environment is under direct influence of these elements and how they communicate in their everyday's working relationships. Harpaz and Fu (2002) stated that work was a basic and important activity for people in modern society, and Bastos (1995) 
described that work was an important sphere in the life of the individual. In this context, communication and organizational environment play a vital role in quality of life and job satisfaction.

For these factors to be realized, managers must always seek to provide conditions for the human resources welfare of the organization, fostering a workplace that is reliable and with clear forms of communication, so that the activities are performed in a pleasant way thus achieving satisfaction and motivation of employees as well as their quality of life.

The quality of life at work is one of the triggers of organizational climate, which has direct connection with the following points: incentives, benefits offered by the company, hygiene and safety (Chanlat, 1999).

According to Rodrigues, Imai, and Ferreira (2000), incentives were a form of compensation due to the employee. They are usually assigned in the form of supplemental compensation to the employee's wages. In many organizations, as an alternative to variable pay, there is a fixed base salary, and the remainder is allocated as an incentive based on performance.

Like variable wages, the incentives may be individual, team driven, or collective. The incentives for individual and group are assigned by merit or according to the productivity of individual and group, respectively. The collective incentives can be awarded on the occasion of anniversaries for the organization, or of certain events (for example, opening a new branch), or simply as a form of participation in the organization, as is the case of equity participation by offering company stock, or distribution of part of profits to employees.

Benefits are defined as a form of unpaid compensation, contrary to the incentives, not dependent on merit or performance of employees. Usually, the benefits are granted to all employees of the organization, except for some benefits only assigned to certain jobs or working groups. Benefits can be in the form of social benefits or other perks.

These benefits act as a form of motivation because they create an organizational climate by meeting the basic needs of employees. When this form of management exists and there is a clear communication of its establishment, employees feel motivated and integrated into the performance of the organizational mission.

\section{Teamwork}

Teamwork is seen as a strategy devised by man to improve the effectiveness of work and to raise the level of worker's satisfaction for being part of a team.

As for the team, it is defined as the number of people working towards a common goal when meeting specific goals, and the formation of the team must consider the individual skills of each member in the development of activities and meeting of goals. There must be respect for the principles of the team, with the interaction of its members, and particularly the recognition of the interdependence of each one so that objectives are met and the team's results are positive.

Souza (2009) explained that teamwork involved setting objectives and targets, division of roles, interpersonal adjustment, conflict resolution, definition of the organization of work and levels of autonomy, and relations with the leader.

Teamwork is an essential element for achieving quality relationships within the company. Team building transforms the company into an entity of social values, because when it preaches the interaction between members, it triggers changes in work relations, and integrates the individual into the organization. 


\section{Interpersonal Relations and Motivation}

The personal relationship between people is the most valuable organization resource and people's ability to interact is the main essence of any administration, because it is through them that agreements are created to ensure the continuation and survival of the organization in this new knowledgeable society (Pinto, 2000).

The knowledgeable society requires that the organization deals with its most important asset, which is human knowledge. The means of production are now not the machinery and equipment, but people's knowledge. Rego (2000) and Moscovici (2001) reported that people think, innovate, and develop, and these are essential factors, on which organizations and work depend. Hence the reason for the importance in investing in training and development of staff administration, because in this process, interpersonal relationship becomes the main factor capable of transforming culture and making the organization more competitive.

According to Gil (1994), staff administration is a specialized branch of science that involves all the actions created for integration of the worker into the organization and increase in productivity.

In the era of digital economy, the Internet and electronic commerce, the relationship between the organization and its suppliers and customers involves people's behavior, management of intellectual capital, management of skills and knowledge that represent new concepts which meant to transform the traditional area of human resources and staff administration, and most recently, the strategic management of people. Grasping and understanding changes and trends forecasting is as vital to managing people as it is managing the company's daily issues (Bahia, 1995).

Large changes in an organization come from people, the way they organize and understand the company and the actions taken to attract them and retain them, but it is necessary and important to understand the needs of the organization to adapt them to their reality because in today's globalized world, characterized by complexity, uncertainty and speed drastically changing the work within organizations, there is a need for organizations to focus on knowledge management and intellectual capital as a competition tool (Chiavenato, 2000).

The human factor is the company's foundation for the implementation and continuity of organizational management. It is important to point out that the competitive environment will leave no room for those who do not prepare themselves to achieve higher levels of efficiency and effectiveness. In general, when it comes to business training, competence is the only considered area, skills fit for the exercise of certain functions. Nobody manages anything without people, and therefore it is necessary to think of continuing education as a mechanism of evolution intended to generate organizational innovation.

For a management to be successful, it must take into account people's conditions and all human conditions such as motivation, desires, frustrations, commitment, courage, despair, interests, personal problems, health problems, and finally the full range of daily life situations.

To be healthy, the company needs to develop its people, not only enhance their skills but also prepare their staff for life, i.e., having life projects, reconciling personal and organizational goals, overcoming obstacles, motivating, turning weaknesses into potential, overcoming discouragement, generating energy to achieve results. However, in the process of achieving results, there must be compatibility between personal and organizational goals and motivation must rely on a particular drive that moves the person from within and has the power to create the necessary commitment to achieve organizational goals (Chiavenato, 2005). 
Based on that, it is said that a person is motivated when they are touched by something, usually something defined by emotional appeals, such as health, love, money, relationships, and desire for consideration. Accordingly, it appears that the commitment is directly tied to interests and its active desire that makes people do something. As explained by Chiavenato (2005), without commitment desire was passive. Interest is a state of mind that exists for all that it is deemed worthy of attention, arouses the curiosity and is considered to be important. So to be interested in the results, one need to see importance in the work they do, their work must have meaning and this is achieved by reconciling the personal goals, interpersonal relationships and skills development.

So it appears that according to how each person thinks and acts, communicates his/her ideas and knowledge, an organizational team must have good interpersonal skills to effectively and efficiently meet organizational goals.

\section{Agribusiness Enterprises}

The agribusiness enterprises of every year increase their global market share and provide status of social and economic importance for Brazil as well, when considering participation in foreign exchange, employment and income generation in the country.

For Welch (2006) Brazil was fabulously rich in natural resources, it is unique in the world for having millions of acres where there is more potential land available for development than in all agricultural land that is cultivated in the USA. Refers to Romano (2011) that the Brazilian participation in international agricultural trade has been growing and this dynamic has allowed another record in trade surplus in the sector in 2010 (U.S. \$63.1 billion), despite the discussion about the loss of competitiveness because of the value rankings of the real. The estimate for 2011 is further expansion of the balance of $2.1 \%$.

The lower rate will be given the higher base of comparison for exports and imports. It is expected new high of commodities, especially soybeans, but the recovery of the leading economies will be crucial for the Brazilian foreign trade.

The country is the third largest exporter of agricultural products worldwide, behind only the U.S. and the European Union. The largest producer and exporter of sugar, coffee and orange juice, also lead foreign sales of ethanol, tobacco, and chicken with great weight in complex soy and meat. And this condition was not threatened in 2010, despite the exchange rate and the logistical problems that hampered shipments in Brazil.

The evolution of prices contributed the most to the national result in 2010, since the volumes in major food chains, have not increased much. Even facing challenges, Brazil's agribusiness sector should be regarded amongst the world leaders, ensuring the sector's contribution to the stability of the economy.

Guanziroli (2006) stated that technological levels achieved by farmers in Brazil reached significant levels that can be measured by increased productivity in the field. This explains, for example, the fact that Brazil has managed to double the production of grain to more than 100 million tons for the harvest of 50.8 million tons achieved in the early 1980s, with the same cultivated area. This field performance was only possible through the use of inputs-primarily seeds, fertilizer and pesticides - the first line available to the industry and the development of workers to cope with new technologies and new market reality of agribusiness. Today, agribusiness enterprises are defined as the sum of productive sectors with the processing of the final product and 
manufacturing inputs, and accounts for nearly one-third of Brazil's GDP and a similar value of total exports of the country.

This development is based on a tripod that involves the farmer, who is the protagonist in the process, the government, which supports the production and science and technology, which are incorporated into the process (ABAG, 2011).

In the state of Mato Grosso do Sul (MS), in the midwest, specifically, in recent years, the developments of agribusiness have suffered crises in certain industries. Cattle, for example, had losses in the embargo on exports of beef produced in MS, due to the diseases occurred in October 2005 that, as Silva and Miranda (2007) was recovering and has increased exports to European countries and other continents, as importers get to know the "green" meat produced here in the state.

In agriculture, competitiveness and development of new technologies have played an important role in the development sector in the region. According to Marion and Segatti (2005), the farmer was turning into rural manager who in addition to worrying about the production, productivity and profitability search, requires people well prepared and motivated to develop their activities within the company and knows they also have to worry about the communication and interpersonal skills of their employees. Their goal is to produce more with fewer resources and for that they need information and integrated and participatory management to the business.

\section{Materials and Methods}

This study includes data from the theoretical, descriptive exploratory method, and field research using a survey as a research tool of the agribusiness ventures. It is also characterized as a multi-case study.

The survey was conducted in a group of five companies in the agribusiness sector, located in Mato Grosso do Sul, in the Grande Dourados area, in that managers have requested the anonymity of their companies in the dissemination of the research results. A survey with open and multiple-choice questions was handed to 168 employees, randomly chosen and who were willing to answer the survey, in a universe of 384 employees. The authors asked respondents who did not exchange information amongst themselves while answering the survey. One hundred and four surveys were answered and returned to researchers, after which the data collection was done, tabulation analysis with the use of statistical software, the description of results and final considerations of the study were also performed.

Industry was not considered in the results of the survey, since all companies belonged to the same industry: production and marketing of grain. The concern, given the demands on managers, was not to make comparisons between data from enterprises to generate non-individualized information.

\section{Discussion and Analysis of Results}

Through the analysis of results was possible to detect as it is communication and interpersonal relationships in organizations surveyed relating to the integration of subsystems, identifying the ability of teamwork, interpersonal communication, conflict, performance, and job satisfaction. In this sense, the survey revealed that $75 \%$ of respondents understand the socio-economic mission of their organization at a higher level and $25 \%$ said they do not have clarity on this issue. 
When asked about whether they work towards the achievement of the tasks according to established routines, $64 \%$ of respondents answered that they perform as requested, but $22 \%$ are not sure if that's exactly what they should have done and $14 \%$ do as they believe the work should be completed.

Fifty percent of respondents answered that they know the organizational goals at a high level, and $50 \%$ were not clear on what were the long-term objectives of the company. It was shown that $42 \%$ of respondents prioritize the system and structure at very high level, 33\% at reasonable levels, and 25\% at a low level.

Forty-eight percent responded that they accept people as they are and 52\% said they seek to adapt to the work. The question was whether they valued relationships with co-workers, $75 \%$ said they highly valued it, and $25 \%$ said they valued it at a median level.

Also the survey found that $61 \%$ of respondents trust people minimally, $25 \%$ responded that they trust people at reasonable levels, $14 \%$ have high trust levels. Moreover, it appears that $32 \%$ responded that they resolve conflicts using the power conferred through the hierarchy, minimally, 50\% responded on average to $18 \%$ would not worry about conflicts at work. It was revealed that 50\% communicate and establish collaboratively their organizational values, beliefs and habits at a median level, $25 \%$ at a small level, and 25\% did not answer this question.

About the benefits offered by the company, it was shown that $72 \%$ are properly addressed, but lack investment in training and education, and $28 \%$ of respondents believe that the subject is irrelevant considering the reality of the state and region.

It was found that only $38 \%$ of respondents feel included in a work team and $62 \%$ did not have this perception about the work environment. Also the data revealed that $48 \%$ of those surveyed have clear communication from the company to employees, the rest were at reasonable levels.

The survey found that the handling of conflict is seen as insignificant by $56 \%$ of respondents and that this affects people's performance in their everyday life.

Regarding the question about satisfaction in their work, $48 \%$ are glad with the work they do, but $52 \%$ responded they were not, $35 \%$ of these revealed that job satisfaction is a consequence of factors related to interpersonal relationships and communication between people.

\section{Conclusions}

The results of this study show that in all the answers, most of the respondents do not have a proper understanding of the importance of communication and interpersonal relationships within the organization.

But it shows that there is much to be improved, especially with regard to the development of people. In this sense, it shows that the investing in continuing education and refresher courses is encouraged, for employee development will certainly make them feel valued by the company, thus the concern to demonstrate and train qualified employees by offering them the opportunity for personal and professional growth, shows increased productivity, reduced costs, reduced employee turnover, and improvement of the quality of life as its benefits. Another important factor of agribusiness enterprises is that they should pay attention and develop the entrepreneurial skills of the staff and corporate managers. 
It appears that the objectives of the research were achieved, demonstrating that investment is needed with regard to the mingling of teams, job satisfaction and research in the area of communication and that information will serve as guides for managers to lead their teams in achieving the goals and business objectives.

It is feasible through research results that companies need to improve forecast, placing people as effective participants in the process, making them feel part of the whole, and socializing internal information.

Another attention deserving point however implicitly revealed by the investigation is the management type, which gives evidence that the processes are still highly centralized with no concern for the development of businesses and individuals who work in them.

Finally, this study has enabled us to learn about the importance of communication and interpersonal relationship in business, in every kind of organization, including agribusiness, as it indicates that if properly developed by managers and workforce, it can become a competitive marketing generators and greater integrator between the company and employees. It is suggested that further studies to be made to deepen this research as this may be considered as an additional driving factor for the management and regional development of agribusiness, being that agribusiness has taken an increasing importance worldwide role for its ability to create the production chain and the power to feed the world population.

\section{References}

ABAG (2011). Association of Brazilian agribusiness. Retrieved from http://abag.sites. srv. br/site/item.asp?c $>$.jan

Bahia, B. J. (1995). Introduction to business communication. São Paulo: Mauad.

Bastos, A. V. (1995). Significance of the work: A study among workers employed in formal organizations. Journal of Business Management, 35, 20-29.

Caparoz, G. P. (2005). Psychological suitability as intervening factor at work. Journal Digital Buenos Aires, 10(88), 25-37.

Chanlat, J. F. (1999). The individual in the organization: Dimensions forgotten. São Paulo: Atlas.

Chiavenato, I. (2000). Transforming human resources: (A center expense) into a profit center (2th ed.). São Paulo: Makroon Books. Chiavenato, I. (2005). Administration of people (2th ed.). Rio de Janeiro: Elsevier.

Guanziroli, C. E. (2006). Agribusiness in Brazil: Prospects and limitations. Working Paper No. 186, Universidade Federal Fluminense. Retrieved from http://www.uff.br/econ/download/tds/UFF_TD186.pdf

Gil, A. C. (1994). Human resource management: A professional approach. São Paulo: Atlas.

Harpaz, I., \& Fu, X. (2002). The structure of maning of work: A relative stability amindst change. Human Relations, 55, $639-667$. Marion, J. C., \& Segatti, S. (2005). Manage agribusiness costs. Costs and Agribusiness Online, 1(1), 10-12.

Moscovici, F. (2001). Interpersonal relationships (11th ed.). São Paulo: José Olímpio.

Pinto, E. (2000). Communication for productivity: What you gain with corporate communications. São Paulo: Quartzolit.

Pires, A. C. T. (2003). Working interpersonal relationships through group dynamics. Journal Career \& Success, 20 , 10-15.

Rego, F. G. T. do. (2000). Corporate communications/corporate communication: Concepts, strategies, systems, structure, and Techniques (11th ed.). São Paulo: Summus.

Rodrigues, R. R. J., Imai, R. Y., \& Ferreira, W. de F. (2000). A space for interpersonal development at work. Study in Psychology, $6(2), 123-127$

Romano, A. (2011). Agrobalança: Should have another good year. Economy \& Businesssection (pp. 12-25).

Silva, T. G. R., \& Miranda, H. G. de. (2007). Economic impacts in the meat industry. Retrivied January 10, 2009, from http://www.cepea.esalq.usp.br/pdf/Artigo_febre_aftosa. pdf

Souza, J. G. de. (2009). Teamwork. Brazilian Association of Human Resources—National Sistema Nacional—ABRH. Retrivied from http://www.abrhrj.org.br/typo/index.php?id=154

Welch, C. (2006). Globalization and the transformation of work in rural Brazil: Agribusiness, rural labor unions, and peasant mobilization. International Labor and Working-Class History, 70(1), 35-60. 